\title{
Infection Rates in Standard vs. Hydrogel Coated Ventricular Catheters
}

\author{
Anthony M. Kaufmann, Tara Lye, Gary Redekop, Angela Brevner, \\ Mark Hamilton, Michelle Kozey, David Easton
}

\begin{abstract}
Background: Infection related to external ventricular drain (EVD) use is a common neurosurgical complication. Modified catheters with a hydrophilic surface may impede bacterial adherence and thereby reduce catheter related cerebrospinal fluid (CSF) infection. Methods: A prospective randomized clinical trial compared the occurrence of CSF infection related to use of either standard silastic or hydrogel coated EVD catheters (Bioglide ${ }^{\circledR}$, Medtronic). Enrolment was available to all adult neurosurgery patients undergoing placement of a first EVD, at three university centers. The catheters were presoaked in a low concentration of bacitracin solution for 5-10 minutes prior to insertion. Bacterial infection was defined by heavy growth in a single CSF sample or light / medium growth in two consecutive samples. A secondary analysis was also conducted for "probable" CSF infection, including patients started on antibiotics after light / medium growth in a single CSF sample. Statistical analyses included Kaplan-Meier survival curve estimates accompanied by Log Rank and Breslow tests. Results: There were 158 randomized patients available to assess for EVD related infection of CSF. The two study groups had similar clinical characteristics including average duration of EVD use (8 \pm 4 days). Definite CSF infection occurred in seven and probable infection in another six (8\% total). Infection incidence rose steadily from day 2 (1\%) to day $11(11 \%)$. There was no difference of daily occurrence of EVD infection between the two catheter types. Conclusions: Infection remains a common hazard in the use of EVD, and we found no reduction of infection using the hydrogel-coated catheters when presoaked in low concentration bacitracin solution.
\end{abstract}

RÉSUMÉ: Taux d'infection des cathéters ventriculaires standards et des cathéters enduits d'hydrogel. Introduction : L'infection reliée à l'utilisation d'un drain ventriculaire externe (DVE) est une complication neurochirurgicale fréquente. Les cathéters modifiés ayant une surface hydrophile pourraient prévenir l'adhésion bactérienne et ainsi réduire le risque d'infection du liquide céphalorachidien (LCR). Méthodes : Il s'agit d'une étude clinique prospective randomisée comparant la fréquence de l'infection du LCR avec l'utilisation de cathéters en silastique standards ou enduits d'hydrogel (Bioglide“, Medtronic). Tous les patients adultes de trois centres universitaires chez qui l'implantation d'un premier DVE était indiquée pouvaient participer à l'étude. Les cathéters étaient trempés dans une solution de bacitracine pendant 5 à 10 minutes avant l'insertion. L'infection bactérienne était définie comme une croissance bactérienne importante à la culture d'un seul échantillon de LCR ou une croissance légère ou modérée à la culture de deux échantillons consécutifs. Une analyse secondaire a également porté sur des cas probables d'infection du LCR, dont les patients ayant reçu des antibiotiques après une croissance légère ou modérée d'un échantillon unique de LCR. Les analyses statistiques utilisées incluaient l'estimation de la courbe de survie de Kaplan-Meier et les tests du log-rank et de Breslow. Résultats : Cent cinquante-huit patients ont été randomisés. Les deux groupes de patients avaient des caractéristiques cliniques similaires dont une durée moyenne d'implantation du DVE de $8 \pm 4$ jours. Une infection certaine a été diagnostiquée chez 7 patients et une infection probable chez 6 patients, soit chez $8 \%$ au total. L'incidence de l'infection augmentait progressivement du jour $2(1 \%)$ au jour $11(11 \%)$. Il n'existait pas de différence quotidienne entre les deux types de cathéters. Conclusions : L'infection demeure une complication fréquente de l'utilisation d'un DVE et nous n'avons pas constaté de diminution du nombre d'infections avec la mise en place d'un cathéter enduit d'hydrogel après pré-trempage dans une solution à faible concentration de bacitracine.

Can. J. Neurol. Sci. 2004; 31: 506-510

External ventricular drains (EVD) are widely incorporated into management protocols for a variety of pathologies involving the central nervous system, primarily as a means to monitor and treat abnormal elevations of intracranial pressure (ICP). Common indications for EVD use are for patients with severe head injury and aneurysmal subarachnoid hemorrhage (SAH), as well as spontaneous intracerebral hemorrhage, stroke, and postoperative ICP monitoring. The reported incidence of EVDrelated cerebrospinal fluid (CSF) infections within the first two weeks of insertion varies between $0 \%$ and $27 \% .^{1-20}$ This risk rises dramatically after the fourth day, but only $30 \%$ of EVD are removed prior to that time. ${ }^{1}$ By the tenth day, the infection risk is $21-100 \% .1,7,8,21$ While such infections are often asymptomatic,

From the Section of Neurosurgery, University of Manitoba, Manitoba, MB (AMK,MK); Community Health Sciences, University of Calgary, Calgary, AB(TL); Division of Neurosurgery, University of British Columbia, Vancouver, BC(GR, AB); Division of Neurosurgery, University of Calgary, $(\mathrm{MH})$; Calgary Laboratory Services, (DE), Calgary, AB, Canada.

ReCEIVED JANUARY 26, 2004. ACCEPTED infinAlform MAy 31, 2004.

Reprint requests to: Anthony M. Kaufmann, University of Manitoba, Health Sciences Centre, GB137-820 Sherbrook St. Winnipeg, MB, R3A1R9 Canada. 
treatment is initiated to prevent infectious complications like meningitis, brain abscess, subdural empyema, and craniotomy infection. ${ }^{8,9,22}$ Standard practice at many centers is to test CSF samples from the EVD either daily or every other day, for evidence of catheter-related bacterial infection or colonization. If detected, a course of antibiotic therapy is initiated and the catheter is removed. ${ }^{23}$ A new EVD must then be inserted with the associated risk of intracranial hemorrhage, ${ }^{9-11,17}$ or the patient is left without potential benefits of ICP monitoring and CSF drainage.

The source of EVD related infection has been attributed to bacterial contamination of the catheter at the time of its insertion. $^{7}$ A hydrogel-coated EVD was developed to resist bacterial cell attachment and growth (Bioglide ${ }^{\circledast}$, Medtronic). The surface of these catheters have strong hydrophilic properties that maintain a thin aqueous surface layer after a brief period of soaking. This "water shield" impedes bacterial adherence ${ }^{24}$ and is also more resistant of blood clot adherence compared to standard EVD catheters. ${ }^{25}$ The hydrogel-coated catheters may also be soaked in antibiotic solution that may adhere to the catheter surface. While such hydrogel-coated EVD are commercially available, there have been no previous studies to assess their clinical effectiveness compared to standard EVD catheters. We report a prospective randomized clinical study examining the daily occurrence of EVD-related CSF infections associated with the use of standard versus hydrogel-coated catheters.

\section{Methods}

The two-group, randomized clinical trial was designed to compare infection rates related to two types of EVD catheters. The study was conducted at three university based neurosurgical centers, where approval was granted by the respective institutional ethics and scientific review boards. Study enrolment was open to all adult patients undergoing a first EVD placement, without suspicion of existing CSF infection or open head injury. Informed consent was obtained from alert and competent patients or designated surrogates. Patients were randomly designated to receive either a $35 \mathrm{~cm}$ hydrogel-coated EVD (Bioglide ${ }^{\oplus}$, Medtronic), or comparable $35 \mathrm{~cm}$ standard silastic EVD catheter. Although the catheters have recognizable appearances, the laboratory personnel analyzing CSF samples were blinded to catheter type.

Protocol required EVD to be presoaked (internally and externally) with Bacitracin antibiotic solution (2000 units/ml) for five minutes prior to insertion. Standard EVD insertion techniques were used, either via twist drill craniostomy, bur hole, or concurrent craniotomy opening. All catheters were tunneled subcutaneously, and attached to standard closed ICP monitoring/CSF drainage systems. Prophylactic intravenous antibiotics were not prescribed in the study protocol, although all antibiotic use was recorded.

Details of presenting diagnosis and insertion technique were recorded by the operating neurosurgeon. The CSF was sampled immediately following EVD insertion and daily thereafter, for routine studies including bacterial culture and sensitivity. An EVD related bacterial infection was defined as heavy growth (>100 colony forming units / $0.1 \mathrm{ml}$ ) on a single CSF sample, or light / medium growth ( $<100$ colony forming units / $0.1 \mathrm{ml}$ ) on two or more consecutive cultures of CSF obtained from the EVD. ${ }^{26}$ A secondary analysis was also conducted for "probable" CSF infection, which included patients who were started on antibiotics after light / medium growth in a single CSF sample.

The occurrence of EVD related infections was recorded only for patients with catheters used for at least 48 hours, as per the Centre for Disease Control (CDC) standard, which requires a device to be in-situ for greater than 48 hours in order for an infection to be considered as device-related. ${ }^{27}$ Positive CSF cultures were not attributed to EVD related infection in patients with concurrent bacteriemia / septicemia caused by the identical bacteria, as these likely represent systemic infection rather than primary EVD related infection. However, this did not occur in the series.

The two study groups were compared for differences in composition using independent t-tests for continuous variables and chi-square analysis with Fisher Exact Test for categorical variables. Confidence was set at 0.05 using two sided tests. Group infection rates were compared using Kaplan-Meier curve estimates and Log Rank and Breslow tests. Potential confounding variables, such as diagnostic category and concurrent intravenous antibiotic use, were assessed in the two study groups using the Cox proportional hazards model.

The projected sample size was based on data from other studies examining the influence of catheter surface modification on infection incidence. ${ }^{28-32}$ Although no randomized control trial of surface modified EVD had been previously undertaken, an intravascular catheter trial had shown a significant reduction of infection ( $2 \%$ vs $14 \%, \mathrm{P}<0.004){ }^{30}$ In the present study, we anticipated a daily EVD infection rate of approximately $0 \%$ in the first three days, $4 \%$ in the first week, and $1 \%$ daily thereafter up to 20 days. Power calculations assumed daily hazard reduction of $60 \%$ with the BioGlide catheter, and a censoring risk of 0.05 of premature withdrawal from the study. Using asymptotic likelihood methods and Monte Carlo simulation, a sample size of 115 per group was determined to provide 0.80 power.

\section{RESUltS}

A total of 227 patients were randomized to either study group. Protocol violations were identified in 28 , including open head injury or pre-existing infection (9), age of less than eighteen years (2), insertion failures with the first catheter (4), and incomplete laboratory data (13). The number of postrandomization exclusions were equally represented in the two study groups (Table 1). Another 41 had EVD use for durations of less than 48 hours, for reasons including death (16), EVD malfunction (10), elapsed indication for use (11) and other nonspecified reasons (4). Amongst all randomized patients (both those excluded and included from infection analyses), catheter malfunction or obstruction occurred in 27 patients (5.2\%), with no significant difference between the standard (15) and hydrogel-coated (12) catheters.

The comparison of EVD-related infections was therefore based on 158 patients. The standard and hydrogel-coated catheter groups had similar presenting diagnoses (Table 2). There was a 3:2 male predominance, and mean patient age was 
Table 1: Patients Excluded from Infection Analyses

\begin{tabular}{lccc}
\hline Reason for Exclusion & Standard & Hydrogel & Total \\
Open Head Injury/Pre-existing Infection & 5 & 4 & 9 \\
Age < 18 Years & 1 & 1 & 2 \\
Insertion Failure on First Attempt & 2 & 2 & 4 \\
Incomplete Lab Data & 8 & 5 & 13 \\
\hline Duration of use < 48 Hours & $(20)$ & $(21)$ & $(41)$ \\
$\quad$ Due to Death & 8 & 8 & 16 \\
$\quad$ EVD Malfunction & 6 & 4 & 10 \\
$\quad$ Elapsed Indication & 5 & 6 & 11 \\
$\quad$ Other Early Removal & 1 & 3 & 4 \\
\hline & $\mathbf{3 6}$ & $\mathbf{3 3}$ & $\mathbf{6 9}$
\end{tabular}

Table 2: Diagnoses of Qualified Subjects

\begin{tabular}{lccc}
\hline Diagnosis & Standard & Hydrogel & Total \\
Closed Head Injury & 33 & 29 & $62(39 \%)$ \\
Aneurysmal SAH & 26 & 35 & $61(39 \%)$ \\
Intracerebral Hemorrhage & 15 & 11 & $26(17 \%)$ \\
Tumor / AVM & 3 & 4 & $7(4 \%)$ \\
Ischemic Stroke & 0 & 2 & $2(1 \%)$ \\
Total & $\mathbf{7 8}$ & $\mathbf{8 0}$ & $\mathbf{1 5 8}(\mathbf{1 0 0 \%})$ \\
\end{tabular}

SAH - subarachnoid hemorrhage

AVM - arteriovenous malformation

\section{Table 3: Organism Occurrence in CSF EVD-Related Infections}

\begin{tabular}{lccc}
\hline Organism Species & $\begin{array}{c}\text { Definite } \\
\text { Infections }\end{array}$ & $\begin{array}{c}\text { Probable } \\
\text { Infections }\end{array}$ & $\begin{array}{c}\text { Total } \\
\text { Infections }\end{array}$ \\
Coagulase Negative Staphylococcus & 4 & 1 & 5 \\
Staphylococcus aureus & 2 & 2 & 4 \\
Klebsiella oxytoca & 1 & 0 & 1 \\
Coryneform bacilli & 0 & 2 & 2 \\
Escherichia coli & 0 & 1 & 1 \\
Total & 7 & 6 & 13 \\
\end{tabular}

$51 \pm 18$ years. The duration of EVD use ranged from two to 22 days ( $8 \pm 4$ days), with no significant differences between the two study groups.

Definite EVD related CSF infection occurred in seven patients $(4.4 \%)$, and another six patients (3.8\%) developed probable infections. This produced a total of 13 observed infections, with seven occurring in standard catheters and six occurring in BioGlide catheters, for an overall infection rate of $8.2 \%$ (Figure). Specific infectious organisms and observed occurrence are listed in Table 3. There was a steady increase of infection incidence between days $2(1 \%)$ and $11(11 \%)$. Analysis

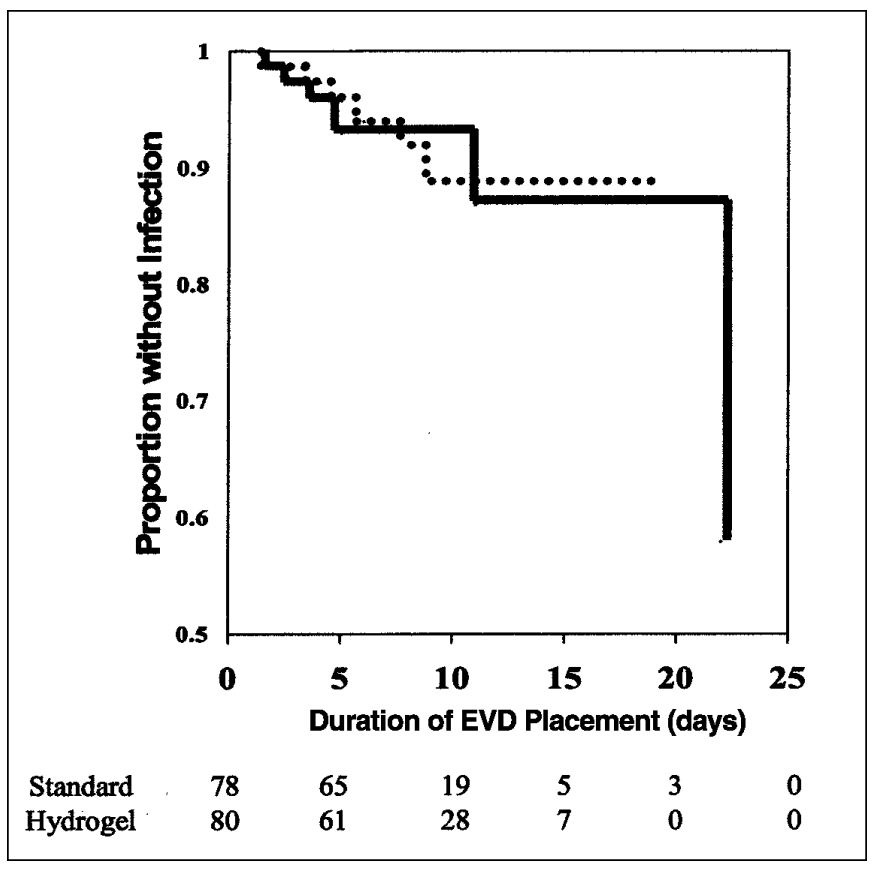

Figure: Graph demonstrating Kaplan-Meier cumulative curves for proportion of patients free of external ventricular drain (EVD) related CSF infection. A number of patients with standard or hydrogel coated catheters that were at risk of infection at 5 day intervals are shown below the figure. There was no statistical difference between the two catheter types in duration of placement in days to onset of infection. Solid line represents standard catheters; the dotted line represents hydrogel-coated catheters.

of Kaplan-Meier curve estimates indicated no statistical difference between the two catheter types in duration to onset of definite infection ( $\log \operatorname{Rank}=0.55, \mathrm{p}>0.46$; Breslow $=0.31$, $\mathrm{p}>0.58$ ), and no differential risk for cumulative hazard function for the two catheter types. Similar results were found when examining all patients with definite or probable CSF infection $(\log$ Rank=0.01, $\mathrm{p}>0.91 ; \quad$ Breslow $=0.05, \quad \mathrm{p}>0.83)$. No relationship was found between the frequency of observed CSF infection and presenting diagnosis or other presenting characteristics. A Cox regression procedure (backwards stepwise) was also used to examine risk of infection adjusted for pre- or postoperative antibiotic use, and no significant difference between the two catheter types was found $(p>0.24)$.

\section{DISCUSSION}

External ventricular drain-related infections continue to adversely impact the management of patients with severe head injury, aneurysmal SAH, and other intracranial pathologies. While these devices have been shown to provide valuable monitoring and therapeutic options that are associated with improved clinical outcome, their use is often limited by the presence or threat of catheter-related CSF infection. The incidence of EVD related infection may be reduced with measures that include tunneling catheters subcutaneously from the insertion site, the use of closed drainage systems rather than open manometer systems, and restriction of system 
manipulations such as flushing and disconnection. ${ }^{33}$ Some neurosurgeons replace the EVD every five to seven days, ${ }^{1,2,8}$ although there is no evidence that this practice reduces the infection rate. ${ }^{26,34-36}$ The use of prophylactic intravenous antibiotics to prevent infection has also been controversial. Several studies have found a reduced infection rate with their use. ${ }^{16,18,19,21}$ However, others have reported no benefit, ${ }^{33,37-39}$ perhaps because the infecting bacteria gain intracranial access at the time of catheter insertion, and then grow upon a favorable catheter surface with little immunological threat within the central nervous system. ${ }^{7}$

The characteristics of the hydrogel-coated EVD catheters have been shown to impair bacterial adherence and surface growth. ${ }^{24}$ It was hypothesized that their use would be associated with a reduced incidence of EVD-related bacterial infections. However, the results of this study did not demonstrate a difference in daily occurrence or total number of infections related to standard versus hydrogel-coated catheters. While our sample size did fall below the number projected in power calculations, there was no trend toward infection reduction. Conversely, a recent trial demonstrated reduced incidence of EVD-related infections associated with the use of an antibiotic impregnated catheter. ${ }^{40}$ Among 288 randomized patients, positive CSF cultures were seven times more frequent in the control versus study groups $(1.3 \%$ vs $9.4 \%, p=0.002)$.

The hydrogel-coated EVD catheter may absorb antibiotic during presoaking, and our protocol included the commonly prescribed operating room practice of presoaking catheters in a dilute bacitracin solution (2000 units/ml). However, this was not expected to provide a high concentration of surface antibiotic. While various catheter-related infections have been effectively reduced in clinical and experimental studies using other techniques of antibiotic coating, ${ }^{41-43}$ there was no approval to apply this to EVD catheters at the time of this study. We were therefore unable to test the potential antibacterial effectiveness of hydrogel-coated catheters presoaked in high concentration of antibiotic solution.

Our study has again found a significant incidence of EVD related CSF infections, although failed to demonstrate any reduction associated with the use of a hydrogel-coated catheter presoaked in low concentration bacitracin solution. Recent approvals for antibiotic coating of EVD catheters may afford the opportunity to assess the effectiveness of presoaking such surface-modified EVD catheters in higher concentrations of appropriate antibiotics.

\section{ACKNOWLedGements}

This study was supported by joint funding from the Calgary Health Region and Medtronics Canada. The authors thank their colleagues who participated in this study, as well as Mrs. CJ Byrnes and Ms. H. Long for assistance in preparing this manuscript.

\section{REFERENCES}

1. Aucoin PJ, Kotilainen HR, Gantz NM, et al. Intracranial pressure monitors. Epidemiologic study of risk factors and infections. Am J Med 1986; 80(3):369-376.

2. Blomstedt GC. Results of trimethoprim-sulfamethoxazole prophylaxis in ventriculostomy and shunting procedures. A double-blind randomized trial. J Neurosurg 1985; 62(5):694697.
3. Chan KH, Mann KS. Prolonged therapeutic external ventricular drainage: a prospective study. Neurosurgery 1988; 23(4):436-438.

4. Chaparro MJ, Pritz MB, Yonemura KS. Broviac ventriculostomy for long-term external ventricular drainage. Pediatr Neurosurg 1991; 17(4):208-212

5. Friedman WA, Vries JK. Percutaneous tunnel ventriculostomy. Summary of 100 procedures. J Neurosurg 1980; 53(5):662-665.

6. Gopinath SP, Robertson CS, Contant CF, et al. Clinical evaluation of a miniature strain-gauge transducer for monitoring intracranial pressure. Neurosurgery 1995; 36(6):1137-1140.

7. Kanter RK, Weiner LB, Patti AM, Robson LK. Infectious complications and duration of intracranial pressure monitoring. Crit Care Med 1985; 13(10):837-839.

8. Mayhall CG, Archer NH, Lamb VA, et al. Ventriculostomy-related infections. A prospective epidemiologic study. N Engl J Med 1984; 310(9):553-559.

9. Narayan RK, Kishore PR, Becker DP, et al. Intracranial pressure: to monitor or not to monitor? A review of our experience with severe head injury. J Neurosurg 1982; 56(5):650-659.

10. North B, Reilly P. Comparison among three methods of intracranial pressure recording. Neurosurgery 1986; 18(6):730-732.

11. Paramore CG, Turner DA. Relative risks of ventriculostomy infection and morbidity. Acta Neurochir (Wien) 1994; 127(12):79-84

12. Ropper AH, Shafran B. Brain edema after stroke. Clinical syndrome and intracranial pressure. Arch Neurol 1984; 41(1):26-29.

13. Rosner MJ, Becker DP. ICP monitoring: complications and associated factors. Clin Neurosurg 1976; 23:494-519.

14. Schultz M, Moore K, Foote AW. Bacterial ventriculitis and duration of ventriculostomy catheter insertion. J Neurosci Nurs 1993; 25(3):158-164.

15. Smith RW, Alksne JF. Infections complicating the use of external ventriculostomy. J Neurosurg 1976; 44(5):567-570.

16. Stenager E, Gerner-Smidt P, Kock-Jensen C. Ventriculostomyrelated infections - an epidemiological study. Acta Neurochir (Wien) 1986; 83(1-2):20-23.

17. Sundbarg G, Nordstrom CH, Soderstrom S. Complications due to prolonged ventricular fluid pressure recording. Br J Neurosurg 1988; 2(4):485-495.

18. Winfield JA, Rosenthal P, Kanter RK, Casella G. Duration of intracranial pressure monitoring does not predict daily risk of infectious complications. Neurosurgery 1993; 33(3):424-430.

19. Wyler AR, Kelly WA. Use of antibiotics with external ventriculostomies. J Neurosurg 1972; 37(2):185-187.

20. Yablon JS, Lantner HJ, McCormack TM, et al. Clinical experience with a fiberoptic intracranial pressure monitor. J Clin Monit 1993; 9(3):171-175.

21. Levin AB, Braun SR, Grossman JE. Physiological monitoring of the head-injured patient. Clin Neurosurg 1982; 29:240-287.

22. Clark WC, Muhlbauer MS, Lowrey R, et al. Complications of intracranial pressure monitoring in trauma patients. Neurosurgery 1989; 25(1):20-24.

23. Ohrstrom JK, Skou JK, Ejlertsen T, Kosteljanetz M. Infected ventriculostomy: bacteriology and treatment. Acta Neurochir (Wien) 1989; 100(1-2):67-69.

24. Cook AD, Sagers RD, Pitt WG. Bacterial adhesion to poly(HEMA)based hydrogels. J Biomed Mater Res 1993; 27(1):119-126.

25. Pearce RS, West LR, Rodeheaver GT, Edlich RF. Evaluation of a new hydrogel coating for drainage tubes. Am J Surg 1984; 148(5):687-691.

26. Stenager E, Gerner-Smidt P, Kock-Jensen C. Ventriculostomyrelated infections - an epidemiological study. Acta Neurochir (Wien) 1986; 83(1-2):20-23.

27. Horan TC, Gaynes RP, Martone WJ, Jarvis WR, Emori TG. CDC definitions of nosocomial surgical site infections, 1992: a modification of CDC definitions of surgical wound infections. Am J Infect Control 1992; 20(5):271-274.

28. Donetz AP, Harvey RA, Greco RS. Stability of antibiotics bound to polytetrafluoroethylene with cationic surfactants. J Clin Microbiol 1984; 19(1):1-3.

29. Hamilton AJ, Orozco J, Narotam P, Bowersock T. Efficacy of vancomycin/tri-iododecyclemethyl ammonium chloride-coated 
ventriculostomy catheters in reducing infection. Neurosurgery 1997; 40(5):1043-1049.

30. Kamal GD, Pfaller MA, Rempe LE, Jebson PJ. Reduced intravascular catheter infection by antibiotic bonding. A prospective, randomized, controlled trial. JAMA1991; 265(18):2364-2368.

31. Trooskin SZ, Donetz AP, Harvey RA, Greco RS. Prevention of catheter sepsis by antibiotic bonding. Surgery 1985; 97(5):547551.

32. Trooskin SZ, Donetz AP, Baxter J, Harvey RA, Greco RS. Infectionresistant continuous peritoneal dialysis catheters. Nephron 1987; 46(3):263-267.

33. Mayhall CG, Archer NH, Lamb VA, et al. Ventriculostomy-related infections. A prospective epidemiologic study. N Engl J Med 1984; 310(9):553-559.

34. Holloway KL, Barnes T, Choi S, et al. Ventriculostomy infections: the effect of monitoring duration and catheter exchange in 584 patients. J Neurosurg 1996; 85(3):419-424.

35. Kanter RK, Weiner LB, Patti AM, Robson LK. Infectious complications and duration of intracranial pressure monitoring. Crit Care Med 1985; 13(10):837-839.

36. Sundbarg G, Nordstrom CH, Soderstrom S. Complications due to prolonged ventricular fluid pressure recording. Br J Neurosurg $1988 ; 2(4): 485-495$

37. Alleyne CH Jr, Hassan M, Zabramski JM. The efficacy and cost of prophylactic and perioprocedural antibiotics in patients with external ventricular drains. Neurosurgery 2000; 47(5):1124-1127.

38. Aucoin PJ, Kotilainen HR, Gantz NM, et al. Intracranial pressure monitors. Epidemiologic study of risk factors and infections. Am J Med 1986; 80(3):369-376.

39. Blomstedt GC. Results of trimethoprim-sulfamethoxazole prophylaxis in ventriculostomy and shunting procedures. A double-blind randomized trial. J Neurosurg 1985; 62(5):694-697.

40. Zabramski JM, Whiting D, Darouiche RO, et al. Efficacy of antimicrobial-impregnated external ventricular drain catheters: a prospective, randomized, controlled trial. J Neurosurg 2003; 98(4):725-730

41. Darouiche RO, Raad II, Heard SO, et al. A comparison of two antimicrobial-impregnated central venous catheters. Catheter Study Group. N Engl J Med 1999; 340(1):1-8.

42. Marik PE, Abraham G, Careau P, Varon J, Fromm RE Jr. The ex vivo antimicrobial activity and colonization rate of two antimicrobial-bonded central venous catheters. Crit Care Med 1999; 27(6):1128-1131.

43. Raad I, Darouiche R, Dupuis J, et al. Central venous catheters coated with minocycline and rifampin for the prevention of catheter-related colonization and bloodstream infections. A randomized, double-blind trial. The Texas Medical Center Catheter Study Group. Ann Intern Med 1997; 127(4):267-274. 